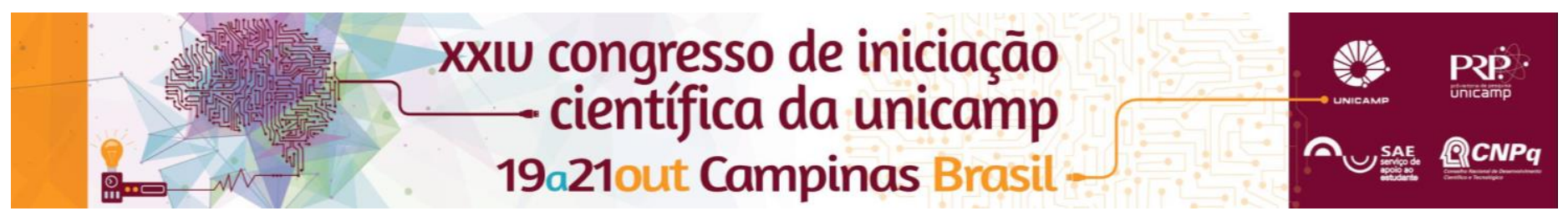

\title{
Otimização do custo logístico para novas plantas fabris através de soluções de Startup: Um olhar estratégico sobre a indústria de bebidas
}

\section{Arthur Lyra Araújo, Vinicius Campanha Sartori, Ricardo Oliveira de Campos.}

\section{Resumo}

A partir da análise das Cinco Forças de Porter sobre a indústria de bebidas brasileira, é possível ter um panorama geral e montar uma estratégia para empresas entrantes. Observa-se uma oportunidade de construir uma empresa startup para oferecer a esses entrantes uma solução de eficiência logística para auxiliar e otimizar a decisão de construção de novas plantas de manufatura de bebidas, inicialmente levando em conta os custos logísticos inbound e outbound.

\section{Palavras-chave}

Análise Estratégica, Startup, Indústria de bebidas.

\section{Introdução}

O setor de bebidas do Brasil é responsável por cerca de $10 \%$ do PIB nacional. Poucos players são responsáveis por uma grande fatia do mercado. Nesse cenário, observamos um crescente número de novas empresas buscando mercados consumidores específicos, compatíveis com seu porte.

O objetivo deste trabalho é a análise qualitativa e estratégica do setor de bebidas brasileiro e a modelagem e proposição de criação de uma empresa startup que visa fornecer suporte logístico a novos entrantes nesse mercado.

\section{Resultados e Discussão}

Ao realizar um estudo analítico, baseado em pesquisa bibliográfica, utilizamos dados das empresas do setor de bebidas no período de janeiro/2008 a outubro/2015. Estes dados foram utilizados para determinar as variáveis críticas do setor. De posse dos números, foi criada uma solução que visa otimizar o custo logístico para implantação de novas plantas fabris.

Inicialmente é feita uma análise das Cinco Forças de Porter aplicada à indústria analisada.

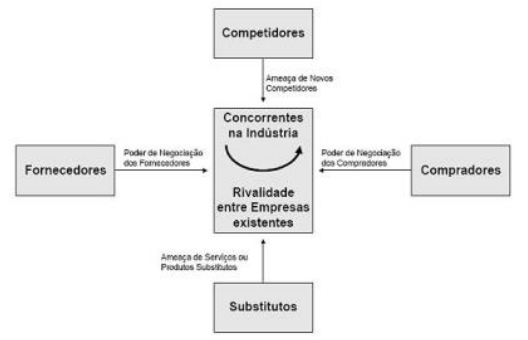

Figura 1. Diagrama das Cinco Forças de Porter

Parte-se então para 0 desenvolvimento da proposta de uma startup, utilizando a proposta de um ciclo de feedback por Eric Ries em The Lean Startup.

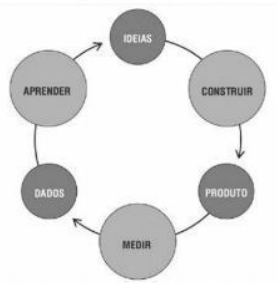

Figura 2. Ciclo de feedback construir-medir-aprender
Partimos então para a construção do modelo matemático de otimização de custo logístico para instalação de novas plantas fabris. O investimento total considerado para o desenvolvimento de uma nova planta foi de $\mathrm{R} \$ 4,6 \mathrm{MM}$. Após a análise do modelo, o ganho logístico foi de $\mathrm{R} \$ 1,92 \mathrm{MM}$ para o ano de 2015 , levando a um retorno de investimento (ROI) em 2,4 anos. Os resultados individuais de cada parâmetro podem ser encontrados no seguinte link: https://drive.google.com/open?id=0B8gQO9bOXS5oMmtR V3pGZFhpNIk

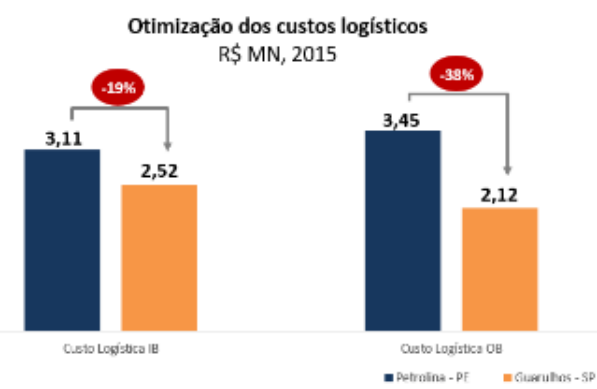

Figura 3. Otimização dos custos logísticos

\section{Conclusões}

Com esse estudo percebe-se uma diminuição considerável no tempo de Retorno Sobre Investimento (ROI) com a aplicação do modelo. A análise estratégica e logística a respeito do setor de bebidas e o cenário econômico mostra-se eficiente no panorama apresentado. Assim, podem ser utilizados conceitos e estratégias inovadores no setor de bebidas brasileiro baseados em empresas startup.

\footnotetext{
1 Ries, E. A Startup Enxuta: Como os empreendedores atuais utilizam a inovação contínua para criar empresas extremamente bem-sucedidas. São Paulo: LEYA Brasil, 2012.

2 PORTER, Michael Eugene. Estratégia Competitiva. Rio de Janeiro: Editora Elsevier Brasil, 1985

3 Osterwalder, A. Business Model Generation: Inovação em Modelos de Negócios. São Paulo: Editora Alta Books, 2011.

${ }^{4}$ Mauborgne, R. e Kim, W.C. A estratégia do Oceano Azul. São Paulo: Editora Campos, 2005

${ }^{5}$ Kawasaki, G. A Arte do Começo. São Paulo: Editora Best Seller, 2004
} 